\title{
Relationship between physiological and seed yield related traits in winter rapeseed (Brassica napus $L$.) cultivars under water deficit stress
}

\author{
Gader Ghaffari ${ }^{1}$, Mahmoud Toorchi ${ }^{2}$, Saeid Aharizad ${ }^{2}$, Mohammad-Reza Shakiba ${ }^{2}$ \\ ${ }^{1}$ Department of Agricultural Engineering, Payame Noor University, East Azarbaijan Province, Iran \\ ${ }^{2}$ Department of Crop Production and Breeding, Faculty of Agriculture, University of Tabriz, Iran
}

Email address:

ghaffari314@yahoo.com (G. Ghaffari)

To cite this article:

Gader Ghaffari, Mahmoud Toorchi, Saeid Aharizad, Mohammad-Reza Shakiba. Relationship between Physiological and Seed Yield Related Traits in Winter Rapeseed (Brassica Napus L.) Cultivars under Water Deficit Stress. American Journal of Agriculture and Forestry.

Vol. 2, No. 6, 2014, pp. 262-266. doi: 10.11648/j.ajaf.20140206.15

\begin{abstract}
Finding the relationship between physiological traits and seed yield components is an important objective in crop breeding programs. Canonical correlation analysis has been adopted to study the strength of association between the physiological traits and seed yield under water deficit stress and to obtain the physiological traits that have the largest effect on seed yield and its components. This study revealed that leaf water potential, relative water content, leaf osmotic potential and chlorophyll index had the largest influence on seed yield and its components under severe water deficit. Under mild water deficit, leaf water potential and relative water content were also important for improving seed yield. Leaf water potential, relative water content, chlorophyll fluorescene and chlorophyll index were had the largest effect on seed yield and its components under well watered condition.
\end{abstract}

Keywords: Canonical Correlation, Water Deficit Stress, Winter Rapeseed

\section{Introduction}

Rapeseed is the third most important oilseed cropoily plant in the world after soybean and palm (FAO, 2007). New seed varieties naturally contain $40-45 \%$ of oil which is used as raw material to produce industrial and hydraulic oil, cleaner, soap and biodegradable plastics (Friedt, 2007). After extracting the oil, the remained oil cake, which contains 38 $44 \%$ high-quality proteins, is used for animal nutrition (Walker and Booth, 2001). Drought and its stress is one of the common environmental stresses which limit farm productions in around 25\% of world's land (Mendham and Salisbury, 1995). Access to water is one of the main limitations in realization of full yield and quality of most species and it may erupt during the whole growth stage or in critical conditions (Parry et al., 2005). Plants employ a range of particular responses in order to minimize the effects of water shortage or to increase water absorbing rate (Morison et al., 2008). The effect of water stress is a function of genotype, stress race, weather condition, growth and development stage of rapeseed (Robertson and Holland,
(2004). Water stress in particular stages of rapeseed phonology affects seed qualitative properties such as percentage of oil and protein and the amount of glucosinolates (Strocher et al., 1995). Liang et al, (1992) by evaluating the morphological and physiological responses to water stress showed that Brassica juncea is more adaptable to water stress than B. napus. The results of Kumar and Singh (1998) indicate that in Brassica oilseeds, the cell turgidity is maintained up to 2.4 Mega Pascal leaf water potential by the genotypes with high osmotic adjustment but with low osmotic adjustment, the fall rate in pressure potential was fast accordingly. Also, Valeric et al, (2002) remarked that when the separately planted rapeseed leaves were positioned under high osmotic- laboratory, huge amount of proline flocked in leaves. Zulini et al, (2002) found a significant correlation between $\mathrm{Fv} / \mathrm{Fm}$ and leaf water potential in stressed plants so when leaf water potential decreases to less than 0.9 Mega Pascals, decrease in Fv/Fm can be observed. Numerous experiments suggest rapeseed yield is influenced by high number of pods per plant or per area unit (Rao and Mendham, 1991). Jensen et al, (1996) reported that the eruption of water stress in vegetative 
growth and flowering stages didn't have significant effect on each rapeseed weight. However, during water shortage in seed filling stage there is reduction in their weight. It has shown that supplemental irrigation of rapeseed increases the number of pods and seeds per pod by extending flowering stage; and it's because of having many leaves in this stage (Kimber and McGregor, 1995).

In spite of a surge in literature on drought tolerance in crops during the past two decades, clear picture on association between physiological characters and seed yield components is yet to emerge. This is mainly because, most of the studies relied on simple correlation coefficients to analyze the relationships. Simple correlations are inadequate to address this complex issue as, physiological and yield components are neither independent from each other nor among themselves. Therefore one has to consider the correlation between these two sets of variables, simultaneously. Canonical correlation, a well-known multivariate technique, has been established for such situations, where one would like to measure the relationship between two sets of interrelated variables. We have adopted canonical correlation analysis to study the strength of association between the physiological traits and seed yield components under severe water deficit stress, mild water deficit stress and well water conditions. Further, we intended to find the physiological characters that have the greatest influence on seed yield and its components under the three conditions.

\section{Materials and Methods}

The experiment was conducted under greenhouse conditions in Agricultural Faculty of Tabriz University, IRAN in $2007-2008$. Temperature during the day was $23^{\circ} \mathrm{C}$ $25^{\circ} \mathrm{C}$ and during the night was $15^{\circ} \mathrm{C}-17^{\circ} \mathrm{C}$ with 14 hours of light. Also the relative humidity was $50-60 \%$.

\subsection{Plant Materials}

The plant material included 12 winter rapeseed cultivars named Zarfam, Okapi, Modena, Licord, Olera, Dexter, Arc-4, Elite, Opera, SLM046, Fornax, and Orient obtained from Agricultural and Natural Resources Research Center of East Azerbaijan province_Iran. Seeds were sown in 8-kilogram flower_ pots with 5 seeds planted in each. Thinning was done at two leaf stage and keep only one plant per pot. Considering that cultivars were winter type, vernalization was done on cultivars. Water deficit stress was imposed from stem elongation to physiological maturity. Gypsum blocks were used in order to control soil moistur. The factorial experiment was done with two factors irrigation at 3 levels: well watered stress $(100 \%$ FC), mild stress ( $75 \%$ FC), severe stress $(50 \% \quad F C)$ and 12 winter rapeseed cultivars in randomized complete block design with 3 replications.

\subsection{Measured Traits}

1. Leaf water potential was measured by Pressure
Chamber; model: Soil Moisture Equipment Crop, Sanata Barbara, CA.

2. Relative water content: The method of MorantManceau et al, (2004) was used. First the Fresh Weight (FW) of samples was measured. Then, the samples were put in distilled water and after 24 hours the Turgid Weight (TW) was measured and after putting samples in $75^{\circ} \mathrm{C}$ Oven the Dry Weight (DW) was measured. Finally the percent relative water content was measured by using formula: $\mathrm{RWC}=\mathrm{FW}-\mathrm{DW} / \mathrm{TW}$ $\mathrm{DW} \times 100$

3. Osmotic potential was measured by Osmometer; model: Osmomat 010, Genotel.

4. Stomata conductance measured by Porometer; model: AP4- Porometer (Delta-T Devices) Cambridge, UK.

5. For chlorophyll fluorescence we used florometer; model: Opti Science, OS-30, USA.

6. Chlorophyll index is determined by Chlorophyll meter; model: SPAD-502, Minolta, Japan.

7. Proline contents were measured by Acid Hydrin method. The plant height, plant dry weight, volume of root, root dry weight, length of siliquae, number of siliquae per plant, seeds per siliquae and 1000-grain weight were measured at the end of growth stage.

\subsection{Statistical Analysis}

Statistical analysis of individual characters was carried out using standard biometrical procedures. The data of individuals were subjected to ANOVA (to partite the variance) and canonical correlation analysis using PROC ANOVA and PROC CANCORR procedures in the SAS program (SAS institute, 1996). Physiological traits and seed yield related traits were considered as independent $(\mathrm{X})$ and dependent $(\mathrm{Y})$ sets of variables, respectively. An overall test for statistical significance of all the five possible canonical correlations from zero was performed using Wilks Lambda (Gittins 1985). The Wilks Lambda was computed using the formula

$$
A=\prod_{i=1}^{s}\left(1-C_{i}^{2}\right)
$$

Where, $\mathrm{Ci}$ is the ith canonical correlation and $\mathrm{s}=\min (\mathrm{p}$, $q), p$ and $q$ are the number of seed yield related and physiological traits studied. Approximate F-test (as per SAS default) was used for assessing the statistical significance of the Wilks Lambda. The structure correlation (Johnson and Wichern 1998) were calculated using the following formula

$$
S_{i(j) k}=\frac{e_{k i(j)} \sqrt{\lambda_{i(j)}}}{\sqrt{\sigma_{k k}}}
$$

Where, i (j) $k=1,2, \ldots$ (q) depends on the number of characters studied in the seed yield and physiological related sets of variables, respectively; $\sigma_{\mathrm{kk}}$ is the variance of the $\mathrm{k}^{\text {th }}$ variable and $\left(\lambda_{i(j)} e_{i(j)}\right)$ are the eigenvalue-eigenvector pairs of the corresponding covariance matrices. The practical 
importance of the canonical correlations was obtained by calculating the redundancy measure (RM) according to Sharma (1996) using the formula

$$
\mathrm{RM}_{\mathrm{Vi.wi}}=\mathrm{AV}\left(\mathrm{Y} / \mathrm{V}_{\mathrm{i}}\right) \times \mathrm{C}_{\mathrm{i}}^{2}
$$

Where, $\mathrm{AV}\left(\mathrm{Y} / \mathrm{V}_{\mathrm{i}}\right)$, variance extracted, is the average variance in $\mathrm{Y}$ variables that is accounted for by the canonical variate $\mathrm{V}_{\mathrm{i}}\left(\mathrm{i}^{\text {th }}\right.$ linear combination of the seed yield related characters).

Total redundancy for the $\mathrm{Y}$ variables $\left(\mathrm{RM}_{\mathrm{y} / \mathrm{x}}\right)$ was computed as

$$
\mathrm{RM}_{\mathrm{Y} / \mathrm{X}}=\sum_{\mathrm{i}=1}^{\mathrm{q}} \mathrm{RM}_{\mathrm{Vi.wi}}
$$

Where, $R M_{V i \text {.Wi }}$ is the redundancy measure as explained above.

\section{Results and Discussion}

Analysis of variance revealed significant differences among the genotypes for all the traits studied under water deficit conditions. The result of canonical correlation analysis carried out between the seed yield traits and physiological traits showed that first three canonical correlations were significant under SW, MW and WW conditions. The first canonical correlation coefficient was 0.88 under SW, 0.74 under MW and $0.79 \mathrm{WW}$ conditions while second canonical correlation coefficient was $0.51,0.57$ and 0.53 under SW, MW and WW conditions. Squared canonical showed that $0.78(\mathrm{SW}), 0.56(\mathrm{MW})$ and $0.64(\mathrm{WW})$ of the variability in yield related traits was explained by the first linear combination of the physiological traits. The contribution of these linear composites for the second canonical variate was $0.25,0.33$ and 0.28 under SW, MW and WW conditions, respectively (Table 1).

Table 1. The first four canonical correlations between physiological and seed yield related traits, squared canonical correlation, cumulative proportion, approximate $F$ and significance level under $S W, M W$ and $W W$ conditions

\begin{tabular}{clllllllllllllll}
\hline \multicolumn{2}{c}{ Canonical correlation } & \multicolumn{4}{c}{ Squared canonical correlation } & \multicolumn{3}{c}{ Cumulative proportion } & \multicolumn{3}{c}{ Approximate F } \\
\hline & SW & MW & WW & SW & MW & WW & SW & MW & WW & SW & MW & WW & SW & MW & WW \\
\hline 1 & 0.881 & 0.748 & 0.798 & 0.777 & 0.560 & 0.637 & 0.874 & 0.595 & 0.689 & 2.35 & 1.76 & 1.98 & 0.001 & 0.023 & 0.008 \\
2 & 0.507 & 0.574 & 0.529 & 0.257 & 0.329 & 0.280 & 0.961 & 0.825 & 0.842 & 0.70 & 1.21 & 1.14 & 0.797 & 0.274 & 0.337 \\
3 & 0.315 & 0.488 & 0.472 & 0.099 & 0.239 & 0.223 & 0.988 & 0.972 & 0.955 & 0.42 & 0.97 & 1.07 & 0.932 & 0.480 & 0.404 \\
4 & 0.206 & 0.235 & 0.319 & 0.042 & 0.055 & 0.102 & 1 & 1 & 1 & 0.31 & 0.41 & 0.80 & 0.867 & 0.799 & 0.537 \\
\hline
\end{tabular}

The intra-set structural correlation which gives the magnitude and direction of the contribution of variables to the variates within domain is presented in Table 2 and Table 3 for yield related and physiological traits, respectively. Among the yield related traits, SPP (0.82), showed the maximum contribution to the first canonical variate in the SW condition followed by SPS (0.72) and Y (0.73). 1000GW was the most influential trait in forming the second and third canonical variate $(0.56)$ and $(0.66)$. Under MW condition, SPP and Y still remained the highest contributing traits $(0.78)$ and $(0.72)$ followed by $1000-\mathrm{GW}(-0.69)$. In formation of the second canonical variate, Y $(0.55)$ was the highest contributors. SPP (0.88) SPS (0.74) and Y (0.90) showed the maximum contribution to the first canonical variate in the WW condition. Y still remained the highest contributing traits $(0.34)$. 1000-GW was the most influential trait in forming the third canonical variate (0.94). Among the physiological traits, CI had the highest contribution (0.87) to the first variate followed by RWC (0.81), LWP (0.77) and LOP (0.67) under SW condition, while, CF and PC were $(0.57)$ and (0.54), respectively. In second variate, $\mathrm{PC}$ was the highest contributing character (0.60). Under MW condition, LWP had the highest contribution (0.93) to the first variate followed by RWC (0.63), CI (0.51) and CF (0.42). CF (0.84) and $\mathrm{CI}$ (0.54) still remained the highest contributing characters. $\mathrm{CF}$ (0.82) had the highest contribution followed by CI (0.81), LWP (0.78) and RWC (0.76) under WW conditions. PC (0.60) was the most influential character in forming the second canonical variate.

Table 2. Structure correlation between physiological traits and their (first four) canonical variates under $S W, M W$ and WW conditions

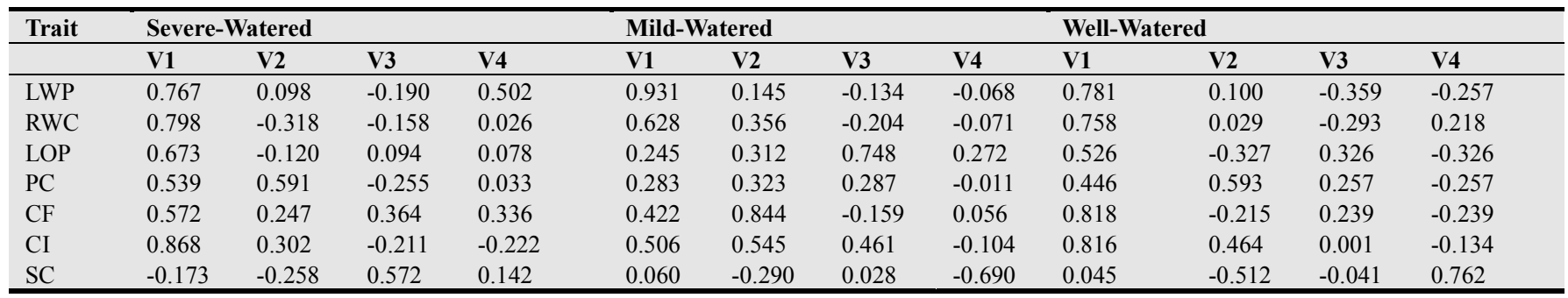

The contribution of the linear function of all the physiological characters for expression of CI, RWC, LWP and LOP were $0.77,0.70,0.68$ and 0.60 percent from the first linear function under SW condition (table 4). Under MW condition, the contribution of the linear function of all the physiological characters for expression of CI, RWC and CF were decreased to $0.38,0.47$, and 0.32 percent but it was 0.70 for LWP. The contribution of the linear function of all the physiological characters for expression of CI, RWC, LWP and CF $0.65,0.60,0.62$ and 0.65 percent from the first 
linear functions under WW condition. Similarly, the contribution of the individual physiological characters to the first three linear functions of the yield-related traits showed $0.72,0.64$ and 0.63 percent of the variability explained by
SPP, SPS and Y, respectively under SW condition (table 5). Under MW environment, the contribution decreased in comparison to SW condition. In WW condition, the results were same as in SW condition.

Table 3. Structure correlation between seed yield related traits and their (first four) canonical variates under $S W$, MW and WW conditions

\begin{tabular}{|c|c|c|c|c|c|c|c|c|c|c|c|c|}
\hline \multirow[t]{2}{*}{ Trait } & \multicolumn{4}{|c|}{ Severe-Watered } & \multicolumn{4}{|c|}{ Mild-Watered } & \multicolumn{4}{|c|}{ Severe-Watered } \\
\hline & $\mathrm{W} 1$ & W2 & W3 & W4 & W1 & W2 & W3 & W4 & W1 & W2 & W3 & W4 \\
\hline SPP & 0.817 & -0.192 & 0.522 & 0.146 & 0.782 & 0.473 & 0.338 & -0.221 & 0.876 & 0.003 & -0.277 & 0.393 \\
\hline SPS & 0.718 & 0.464 & -0.088 & 0.510 & 0.439 & 0.428 & -0.570 & 0.546 & 0.736 & 0.135 & 0.201 & -0.630 \\
\hline 1000-SW & -0.480 & 0.563 & 0.663 & 0.110 & -0.694 & 0.491 & 0.501 & 0.157 & -0.153 & 0.293 & 0.942 & -0.046 \\
\hline $\mathrm{Y}$ & 0.726 & 0.090 & 0.390 & 0.558 & 0.717 & 0.549 & 0.309 & 0.296 & 0.896 & 0.345 & -0.089 & 0.266 \\
\hline
\end{tabular}

Table 4. Correlation of physiological traits contributing to the first four variates of seed yield related traits under $S W$, $M W$ and $W W$ conditions

\begin{tabular}{|c|c|c|c|c|c|c|c|c|c|c|c|c|}
\hline \multirow[t]{2}{*}{ Trait } & \multicolumn{4}{|c|}{ Severe-Watered } & \multicolumn{4}{|c|}{ Mild-Watered } & \multicolumn{4}{|c|}{ Well-Watered } \\
\hline & W1 & W2 & W3 & W4 & W1 & W2 & W3 & W4 & W1 & W2 & W3 & W4 \\
\hline LWP & 0.676 & 0.060 & -0.060 & 0.103 & 0.697 & 0.083 & -0.065 & -0.016 & 0.623 & 0.053 & -0.170 & -0.082 \\
\hline RWC & 0.703 & -0.161 & -0.050 & -0.005 & 0.470 & 0.204 & -.099 & -0.016 & 0.606 & 0.015 & -0.138 & 0.069 \\
\hline LOP & 0.594 & -0.061 & 0.029 & -0.016 & 0.183 & 0.179 & 0.366 & 0.064 & 0.420 & -0.173 & 0.026 & -0.104 \\
\hline $\mathrm{PC}$ & 0.476 & 0.300 & -0.080 & -0.007 & 0.212 & 0.185 & 0.140 & -0.028 & 0.356 & 0.314 & 0.215 & -0.082 \\
\hline $\mathrm{CF}$ & 0.504 & 0.125 & 0.115 & 0.069 & 0.316 & 0.485 & -0.077 & 0.013 & 0.653 & -0.114 & -0.160 & -0.075 \\
\hline $\mathrm{SC}$ & -0.153 & -0.130 & 0.180 & 0.029 & 0.045 & -0.167 & 0.014 & -0.162 & 0.036 & -0.271 & -0.019 & 0.243 \\
\hline
\end{tabular}

Table 5. Correlation of seed yield related traits contributing to the first four variates of physiological traits under SW, MW and WW conditions

\begin{tabular}{|c|c|c|c|c|c|c|c|c|c|c|c|c|}
\hline \multirow[t]{2}{*}{ Trait } & \multicolumn{4}{|c|}{ Severe-Watered } & \multicolumn{4}{|c|}{ Mild-Watered } & \multicolumn{4}{|c|}{ Well-Watered } \\
\hline & V1 & V2 & V3 & V4 & V1 & $\mathbf{V 2}$ & V3 & V4 & V1 & V2 & V3 & V4 \\
\hline SPP & 0.720 & -0.097 & 0.164 & 0.030 & 0.585 & 0.272 & 0.165 & -0.052 & 0.699 & 0.002 & -0.131 & 0.125 \\
\hline SPS & 0.633 & 0.235 & -0.027 & 0.106 & 0.328 & 0.246 & -0.278 & 0.128 & 0.588 & 0.072 & 0.095 & -0.201 \\
\hline $1000-S W$ & -0.423 & 0.285 & 0.209 & 0.022 & -0.519 & 0.282 & 0.245 & 0.037 & -0.122 & 0.155 & 0.445 & -0.015 \\
\hline $\mathrm{Y}$ & 0.640 & 0.045 & 0.123 & 0.115 & 0.537 & 0.315 & 0.151 & 0.069 & 0.714 & 0.183 & -0.042 & -0.085 \\
\hline
\end{tabular}

\section{Discussion}

Canonical correlation analysis was carried out to identify how physiological characters influence the seed yield traits under SW, MW and WW conditions in winter rapeseed cultivars. Results suggested that CI was the most important character followed by RWC, LWP and LOP under SW condition. In the MW conditions, LWP was the most important character followed by RWC, CI and CF. CF was the most important character followed by CI, LWP and RWC under WW conditions. Pirdashti et al. (2009) observed positive and significant relationship of CI, PC and RWC with seed yield in rice cultivars under drought stress. Pirevatlou et al. (2008) showed positive correlation of CI with seed yield and leaf area index in wheat genotypes under drought stress.

The interrelationships between physiological characters and seed yield-related traits clearly identified the importance of CI, LWP, CF, RWC and LOP under SW, MW and WW conditions. Therefore, the contribution of physiological characters on seed yield under stress condition is more important than well-watered condition. In fact CI, LWP, CF, RWC and LOP can be considered as proper criteria for selecting cultivars for high yield.

\section{Abbreviation}

LWP: Leaf Water Potential, RWC: Relative Water Content, LOP: Leaf Osmotic Potential, PC: Proline Content, CF: Chlorophyll Fluorescence, CI: Chlorophyll Index, LSC: Leaf Stomata Conductance, PH: Plant Height, PDW: Plant Dry Weight, RV: Root Volume, RDW: Root Dry Weight, SL: Siliqua Length, SPP: number of Siliqua Per Plant, SPS: Seeds Per Siliqua, 1000-SW: 1000-Seed Weight, SY: Seed Yield, SS: Severe Stress, MS: Mild Stress, WW: Well Watered.

\section{References}

[1] FAO, 2007. http:// faostat. fao. org/.

[2] Friedt, W., Snowdon, R., Ordon, F., and Ahlemeyer, J. 2007. Plant Breeding: Assessment of genetic diversity in crop plants and is exploitation in breeding. Progress in Botany, 168: 152177. 
[3] Gittins, R. 1985. Canonical analysis, A review with applications in ecology. Springer-Verlag, Berlin. pp, 56-85.

[4] Jensen, C.R., Mogensen, V.O., Mortensen, G.., Fieldsend, J.K., Milford, G.F.J., Anderson, M.N., and Thage, J. H. 1996. Seed glucosinolate, oil and protein content of field-grown rape (Brassica napus L.) affected by soil drying and evaporative demand. Field Crops Research, 47: 93-105.

[5] Johnson, R.A. and Wichern, D.W. 1998. Applied multivariate statistical methods (4 ${ }^{\text {th }}$ edition). London-Prentice Hall. Englewood Cliffs, pp, 65-85.

[6] Kimber, D.S. and McGregor, D.I. 1995. The species and their origin, cultivation and world production. In: Kimber, D.S. and McCregorceds, D.I. (eds.). Brassica oilseeds. CABI, PP: 1-7.

[7] Kumar, A. and Singh, D.P. 1998. Use of physiological indices as a screening technique for drought tolerance in oilseed Brassica species. Annals of Botany, 81: 413-420.

[8] Liang, Z.S., Diang Z.R., and Wang, S.T. 1992. Study on types of water stress adaptation in both Brassica napus L. and B. juncea L. Acta Botanica Boreali, Occidentalia Sinica., 12(1): $38-45$.

[9] Mendham, N.J. and Salisbury, P.A. 1995. Physiolog of Crop development, growth and yield. In: Kimber, D. and McCregor. D.I. (eds). Brassica oilseeds, CABI, Pp: 11-64.

[10] Morant-Manceau, A., Pradier, E., and Tremblin, G. 2004. Osmotic adjustment, gas exchanges and chlorophyll fluorescence of a hexaploid triticale and its parental species to salt stress. Journal of Plant Physiology, 169: 25-33.

[11] Morison, J.I., Baker, N.R., Mullineaux, P.M., and Davies, W.J. 2008. Improving water use in crop production. Philosophical Transactions of the Royal Society of London. Series B: Biological Science, 363: 639-658.

[12] Parry, M.A.J., Flexas, J., and Medrano, H. 2005. Prospects for crop production under drought: Research priorities and future directions. The Annals of Applied Biology, 147: 217-226.

[13] Pirdashti, H., Sarvestani Z.T., and Bahmanyar, M.A. 2009.
Comparison of physiological responses among four contrast rice cultivars under drought stress conditions. Proceedings of World Academy of Science. Engineering and Technology, 37: 2070-3740.

[14] Pirevatlou, A.S., Aliyev, R.T., Hajieva, S.I., Javadova S.I., and Akparov, Z. 2008. Structural changes of the photosynthetic apparatus, morphlogical and cultivation responses in different wheat genotypes under drought stress condition. Genetic Resources Institute. Bako Republic of Azerbaijan, 14: 123130.

[15] Rao, M.S.S., and Mendham, N.J. 1991. Soil-plant-water relation of oilseed rape (Brassica napus and B. compestris). Journal of Agricultural Science Cambridge, 197: 197-205.

[16] Robertson, M.J. and Holland, J.F. 2004. Production risk of canola in the semi-arid subtropics of Australia. Australian Journal of Agricultural Research, 55: 525-538.

[17] SAS Institute, Inc. 1996. SAS language guide for personal computers. Edition 6.12, Carry, NC, USA.

[18] Sharma, S. 1996. Applied multivariate techniques. John Wiley and Sons, New York, pp, 245-256.

[19] Strocher, V.L., Boathe I.G., and Good, R.G. 1995. Molecular cloning and expression of a turgor gene in Brassica napus. Plant Mol Biol., 27: 541-551.

[20] Valeric, H.R., Sulpice, R., Lefort, C., Maerskack, V., Emery, N., and Larher, F.R. 2002. The suppression of osmoinduced proline response of Brassica napus L. var. Oleifera leaf discs by polyunsatutated fatty acids and methyl-jasmonate. Plant Science, 164: 119-127.

[21] Walker, K. C. and Booth, E. J. 2007. Agricultural aspects of rape and other Brassica products. European Journal of Lipid Science Technology, 103: 441- 445.

[22] Zulini, L., Rubinigg, M., Zorer, R., and Bertamini, M. 2002. Effects of drought stress on chlorophyll fluorescence and photosynthetic pigment in grapevine leaves (Vitis vinifera $\mathrm{cv}$. White Riesling). www. Actahort. org / html. 